\title{
Crisis cards and self-help crisis initiatives $^{\dagger}$
}

\author{
Kim Sutherby and George Szmukler
}

The concept of a 'crisis card' originated in the voluntary sector as an advocacy tool for use in mental health emergencies. This type of self-help initiative, and variations which include advance planning for mental health crises, are becoming more common, and have received Government and media attention (Brindle, 1993). The Health Committee's Fifth Report to the House of Commons (1993) on 'Community Supervision Orders' included evidence given by Survivors Speak Out on the use of crisis cards or treatment contracts as an optional alternative to community supervision orders. Survivors Speak Out described how a user, "when in a rational state of mind, can set out in writing (on a crisis card) how they would like to be treated in circumstances when they are not the best judge of their own interests". The Government's response was to encourage the informal use of crisis cards and the development of best practice and guidance on their use bearing in mind the central role of the user (Department of Health, 1993). They also recommended that ways of amending the law to provide for crisis cards to be legally effective should be examined. The Report of the Inquiry into the Care and Treatment of Christopher Clunis recommended that the Royal College of Psychiatrists should design a card for mentally ill people. This appeared to be a response to the identifled need for improved provision of information, communication and liaison across geographical boundaries where necessary (Ritchie et al. 1994).

As part of a consultation to assist in the development of the Camberwell Crisis Card Project a telephone survey of national and local user groups was carried out to determine the types of crisis card already in use, the approximate numbers of cards in circulation and users experiences. The national and regional offices of MIND. MindLink, Manic Depression Fellowship. Survivors Speak Out, SANE, National Schizophrenia Fellowship. UK Advocacy Network (UKAN), and International Self Advocacy Alliance

'See editorial p. 3, this issue. were contacted and as a result of information gained, further enquiries were made to people or organisations known to be using or developing cards.

\section{Findings}

\section{Crisis cards}

International Self Advocacy Alliance/Survivors Speak Out

The first card to be used in this country was developed by the UK-based International Self Advocacy Alliance and jointly launched with Survivors Speak Out in 1989. Survivors Speak Out recently recirculated their membership of approximately 700 with the card and updated guidelines including advice on completing an advance directive. They have also distributed approximately 500 other cards and guidelines to non-members who have expressed an interest. Prior to this they estimate to have distributed 2000 copies of the card and an earlier version of the guidelines. One of the main features of this card is that it allows a user to nominate a friend or relative to be contacted in a crisis and asked to attend. The card also allows space for a user to supply any information they wish and to request specific actions to be carried out. Survivors Speak Out are tolerant of others copying and adapting their card and similar versions are used by MIND groups in Oldham, Rochdale. Thanet. the Brent mental health user group, BUG (Bromley User Group), Milton Keynes Community Health Council and Lewisham Social Services.

To date the only published report of a crisis card being used in an emergency has been of the type circulated by Survivors Speak Out and adaptated by Thanet MIND (Bewick, 1995).

\section{Manic Depression Fellowship}

Since approximately 1990 the Manic Depression Fellowship have provided a card for their membership of over 4000, which includes the address and telephone number of the charity. the name of the member and provides space for information to be provided on the detalls of 
someone to be contacted 'in case of need', with the date and current medication. The card does not include space for the user to include their wishes about treatment. The organisation has recently published a book on self-management of manic depression (Manic Depression Fellowship, 1995) which guides the user through techniques and strategies that users have found helpful. This book is accompanied by a card for the user to complete and carry describing their selfmanagement techniques 'when going high' on one side, and 'when depressed' on the other.

\section{The Camberwell Crisis Card or Joint \\ Crisis Plan}

A pilot project has been carried out by the authors and funded by the National Health Service Executive to examine the feasibility of introducing a form of crisis card or joint crisis plan in a sectorised community mental health service in Camberwell. Users are provided with a 'menu' of suggested headings for information to be included on a card, compiled from existing voluntary sector crisis cards and the Lewisham social services crisis card, with other headings including identification of first signs (Birchwood et al, 1989), added by the researchers. Users are offered a meeting with the clinical team to allow an informed discussion of the type of information or crisis plan to be included on the card while allowing the user the final choice. The user can include as much or as little information as they wish from the four sections: contact details; 'Current Care and Treatment Plan'; an advance plan for 'Care in a Crisis'; and a section on 'Practical Help in a Crisis', which summarises the socially orientated 'Hospital planning sheet' of the Lewisham system. The information chosen is then transferred to a double sided A4 sheet that folds to fit inside a plastic wallet for the user to carry. Copies are provided for whoever the user chooses. Forty users suffering from a severe mental illness characterised by repeated admissions developed a joint crisis plan in the study period (1995-1996) and a detailed follow-up is in progress.

Crisis cards combined with self-help crisis initiatives

\section{Lewisham Social Services}

In Lewisham a system of crisis cards and personal information sheets was developed by a social worker, Marie Diggins, and launched in September 1994 to complement the work of the adult early intervention service. The system has four components: a crisis card of similar design to the Survivors Speak Out model; an option for the nominee's details to be available on a database accessible by phone 24 hours a day; a hospital planning sheet and a financial planning sheet. The hospital planning sheet contains a list of questions prompting the user to record arrangements or plans that they would like to come into effect should they be admitted to hopsital and are generally of a social nature e.g. arrangements for children, cancelling services. Marie Diggins had observed how users admitted to hospital in an emergency had sometimes been discharged to a home that had been burgled as a result of the obvious signs of an absent occupant (e.g. milk bottles on the step) precipitating the user into a further crisis. The hospital planning sheet was designed to prevent this. Similarly the financial planning sheet prompts the user to record necessary details of benefits, rent etc., and to consider whether to arrange for someone to deal with their financial affairs should they become unwell. Neither the hospital nor financial planning sheets are designed to be carried by the user. Approximately 45 users in Lewisham are currently known to be using at least one component of the system. Users were involved in the development of the system and close links with the Brixton Sanctuary led to the inclusion of elements in the Direct Power Resource Pack. The Lewisham scheme is currently distributed via the adult social work teams, Lewisham Users Forum (LUF), Lewisham MIND, and Lewisham Black Mental Health Forum (ISIS). Southwark Social Services are currently considering piloting the scheme in the north of the borough.

\section{Advocard}

A small pilot advocacy scheme, now in its second year, funded by the Scottish Office (Mental Illness Specific Grant) to provide training for volunteer advocates and provide a version of a crisis card for mental health service users in north-east Edinburgh. Most formal advocacy schemes cannot provide a quick response in an emergency and appointments have to be set up in advance. The aim of this project is to enable trained advocates to be contacted quickly as a result of the card and to provide advocacy in a crisis. This card (Advocard) gives the advocate's name and contact details, other contact details (e.g. general practitioner), and allows space for medication and other information to be taken into account. Each card-holder and advocate agree a plan about what the card-holder might want from any possible treatment, how actively they would wish to be represented and the availability of the representative. This plan is kept separately from the card and signed by both parties but is not legally binding in Scottish law and is not developed collaboratively with service providers. To date 12 advocates have received training and are being matched to card-holders. The project will include an evaluation but to date no card-holders have reported the use of their card. 


\section{Self-help crisis initiative \\ Direct Power}

This is a resource pack jointly published in 1995 by the Community Support Network, Brixton Community Sanctuary, Pavilion Publishing and MIND to provide practical guidance for users on self empowerment, advocacy and care planning (Leader, 1995). Approximately 1000 copies have been sold to date. This pack aims to guide people with mental health problems through the necessary steps to complete a self-assessment and prioritise their needs. It recommends that the user complete an enclosed partnership agreement with service providers detailing the services to be provided. It includes a 'hospital information sheet' and 'financial information sheet' as developed by Marie Diggins at Lewisham Social Services, and an 'aftercare checklist' for users to prepare for discharge from hospital which covers a range of social and psychiatric arrangements (e.g. next out-patient appointment, whether a benefits check has been carried out). It also includes notes for mental health workers on explaining and helping service users to use Direct Power. Although not in a form that could be easily carried out with the user it incorporates elements of advance planning.

\section{Comment}

Crisis cards have been enthusiastically adopted by the voluntary sector and a significant number have now been distributed. However, it is not known how many of the cards that have been distributed have been completed by users or how often and to what effect they have been used in mental health emergencies. Our enquiries revealed a number of users who had completed or carried a card, but if there was a significant number of users utilising their cards this was not evident from our enquiries. User-held records have in the past been developed to aid communication between general practitioners and psychiatrists (Essex et al, 1990) for the severely mentally ill but not specifically with the aim of facilitating care in a crisis.

The typology of crisis cards or self-help crisis initiatives includes: format - a user-held record designed either to be carried with the user (crisis card) or to be kept for reference by the user (a self-help crisis initiative); and method of development - either developed by the user (crisis card) or developed in collaboration with their treatment team (what we term 'a joint crisis plan'). In theory a self-help crisis initiative could be either of these.

The functions of crisis cards/self-help crisis initiatives are: (a) provision of information

(i) names and addresses of formal and informal carers

(ii) current care and treatment plan

(b) an assessment of past crises

(i) recognition of what helps or does not help in crisis

(ii) recognition of triggers for relapse/first signs of relapse

(iii) recognition or development of selfmanagement techniques

(c) an advocacy tool for crisis

(i) to nominate advocate and contact them in a crisis

(ii) to record an advance directive or refusal of treatment

(d) advance plans for care in a crisis

(i) what to do at the first signs of relapse (including self-management techniques)

(ii) to record advance statements about the care the user would prefer in a crisis

(iii) to record a collaborative plan with service providers (joint crisis plans only)

(iv) to record social or practical plans in the event of an admission.

(A copy of a joint crisis plan template is available upon request from $K$. S.)

In their evidence to the House of Commons Select Committee, Survivors Speak Out supported the notion of treatment contracts where users negotiate packages of care and interventions with their psychiatrist for use on future occasions when they are incapable of making a decision. While existing voluntary sector crisis cards are completed solely by the user to assist in expressing their views and contacting advocates, a crisis card negotiated between the user and service provider has additional potential. The benefit for users of a negotiated crisis plan is that it allows them greater influence over the care they may receive in a crisis and the opportunity for informed dialogue with health professionals (Sommerville, 1995). For clinical teams a collaborative approach may improve engagement and cooperation with the ensuing treatment plan while improving the therapeutic alliance. Although joint planning is intended to be part of the Care Programme Approach this usually involves planning of maintenance care rather than care in the event of a crisis or relapse. The degree of emphasis on the central role of the user may also vary. This type of collaboration between users and mental health teams tends to be viewed with suspicion by both parties. With appropriate safeguards for the autonomy of the 
user and clinical appropriateness of ensuing plans, joint crisis planning may have potential.

\section{Acknowledgements}

This work was supported by a grant from the NHS Executive and undertaken while $K$. M. was a research senior registrar at PRiSM. Institute of Psychiatry. We would like to thank Ms Adina Halpern, formerly legal adviser to MIND, for her advice and comments.

\section{References}

BEwICK, S. (1995) Playing crisis card for safety (letter). The Ferret: The Newspaper for Caring Services in Kent, 50.

BirCHWOOD, M.. SMmt, J., MACMiLAN, F., et al (1989) Predicting relapse in schizophrenia: the development and implementation of an early signs monitoring system using patients and families as observers, a preliminary investigation. Psychological Medicine, 19, 649-656.

BRINDLE, D. (1993) Card gives user say in treatment. Guardian, 8 July.
DEPARTMENT OF HEALTH (1993) Community Supervision Orders: Government Response to the Fifth Report from the Health Committee (Session 1992-1993). London: HMSO.

Essex, B., Doig, R. \& Renshaw, J. (1990) Pilot study of records of shared care for people with mental illnesses. British Medical Journal, 300, 1442-1446.

HOUSE OF COMMONS HEALTH COMMITTE (1993) Health Committee Fufth Report to the House of Commons. Community Supervision Orders. London: HMSO.

Leader, A. (1995) Direct Power. Brighton: Pavilion Publishing.

MANIC DEPRESSION FELLOWSHIP (1995) Inside Out: A Guide to Self Management of Manic Depression. Kingston Upon Thames: Manic Depression Fellowship.

RITCHIE, J. H., Dick, D. \& Lingham, R. (1994) The Report of the Inquiry into the Care and Treatment of Christopher Clunis. London: HMSO.

SOMMERVILE, A. (1995) Remembrance of conversations past: oral advance statements about medical treatment. British Medical Journal, 310. 1663-1665.

Kim Sutherby, Senior Registrar, *George Szmukler, Consultant Psychiatrist, Maudsley Hospital, Denmark Hill, London SE5 8AZ

*Correspondence

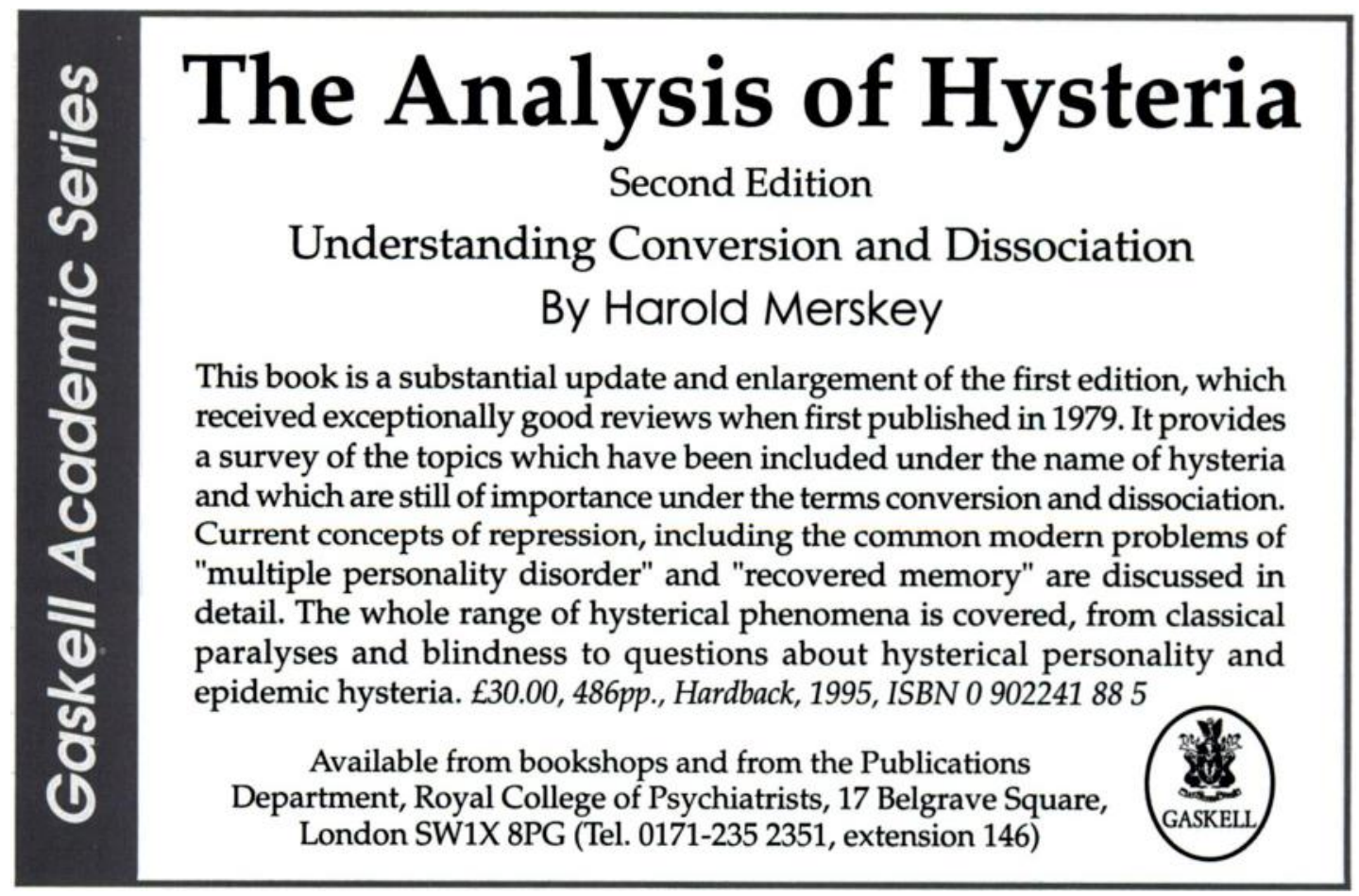

